\title{
Models of Relationship between Emotional, Spiritual, Physical and Social Intelligence, Resilience and Burnout among High School Teachers
}

\author{
Abdul Aziz Ismail, Tajularipin Sulaiman", Samsilah Roslan \\ Faculty of Educational Studies, Universiti Putra Malaysia, 43400 Serdang, Malaysia
}

Received October 27, 2019; Revised December 2, 2019; Accepted December 24, 2019

Copyright $\bigcirc 2020$ by authors, all rights reserved. Authors agree that this article remains permanently open access under the terms of the Creative Commons Attribution License 4.0 International License

\begin{abstract}
Burnout is a condition that can affect a person's work performance. Among the internal factors that contribute to burnout are emotional intelligence, spiritual intelligence, social intelligence, physical intelligence and resilience. This study explores the relationship among these internal factors toward the occurrence of burnout. A relationship model between variable of study was created based on the findings of the study. Instruments related to emotional, spiritual, social and physical intelligence and burnout have been distributed to 377 students of secondary school teachers throughout Selangor as a sample of chosen research using random-stratified sampling and cluster sampling. This study utilizes two approaches in analyzing data, which consist of descriptive statistics of IBM SPSS software statistics 22.0 and inferential statistics using advanced modeling analysis Structured equations (SEM) through the software Analysis of Moment Structure (AMOS) 22.0. The results of correlation analysis have shown that there is direct relationship for all intelligence factors against burn out. All variables have affected burnout except social intelligence. The findings of the study to demonstrate a model of emotional intelligence, social intelligence, physical intelligence, spiritual intelligence and resilience with burnout have reached the concurrence value. Teachers equip themselves with the intelligence and have resilience in carrying out its duties to increase the students ' achievement, thereby encouraging their excellence. The predictor of emotional, spiritual, physical intelligence and burn-outs is an important indicator to certain stakeholder such as Ministry of Education Malaysia to improve vital elements to choose a teacher and courses that should be implemented to the teacher to prevent burnout from occurring.
\end{abstract}

Keywords Intelligence, Internal Factor, Burnout, School Teachers, Emotional Exhaustion

\section{Introduction}

Burnout is a condition in which the individual involved is said to be physically, mentally and emotionally exhausted. According to Blazer (2010) burnout is a state of physical, mental, and emotional exhaustion from chronic stress. It is characterized by feelings of isolation, carelessness, indifference, low self-esteem, loss of interest in work, and inability to perform daily tasks. Maslach, Schaufeli and Leiter (2001) further developed the concept of burnout by explaining that there are three main things: emotional exhaustion, depersonalization and declining personal achievement. Emotional exhaustion is a situation in which an emotional need for something exceeds an individual's emotional source. Depersonalization is a personal psychological disorder in life while a decline in personal achievement is a negative self-assessment of one's achievement. Burnout is a condition that can affect a person's work performance. According to Anbar and Eker (2008), a lot of professions are exposed to burnout. Previous studies have shown that teachers' careers are among the jobs most exposed to burnout. This is because teachers need to connect with a large number of students, colleagues, parents and the local community in a variety of ways. Whereas Cherniss (1995) and Maslach and Schaufel (1993) say there are four factors that contribute to burnout. These factors are engagement with service recipients, individuals, work environments and societies. Maslach et al., (2001) explained that there are two main factors that cause burnout, namely the condition factor and the individual factor. They say that the factors for burnout conditions occur due to job characteristics, job description and job attitude. In addition to demographic factors, Maslach et al., (2001) described personality traits such as 
resilience or individual resilience affecting burnout. Low resistance will cause burnout. According to Brock and Grady (2002) individuals who are said to be burnout are usually associated with physical, intellectual, social, emotional and spiritual conditions. This study examines the internal factors that contribute to burnout namely emotional intelligence, spiritual intelligence, social intelligence, physical intelligence and resilience.

Emotional intelligence refers to one's ability to make sense and convey the right emotions, to use emotions to aid thought processes, to understand emotions, to assist thought processes and to understand emotions and to manage emotions in oneself and others. Mayer and Salovey (1997) state that individuals with emotional intelligence will be able to manage emotions, deal with stress, and deal with failure more effectively. This condition can prevent them from burnout risk. The findings from Pishghadam and Sahebjam's (2012) study of emotional intelligence consistently show that there is a relationship between emotional intelligence and burnout, which has also been proven by the study of Saiiari et al., (2011) that proved a significant negative relationship between emotional intelligence and burnout among sports teachers. This indicates that individuals with high emotional intelligence will be able to reduce their risk of burnout.

Spiritual intelligence refers to the individual's capacity for knowledge, attitude or character that are formed in the heart as a result of understanding and evaluation. It is based on religious elements and pure values and is translated into action or action. According to Zohar and Marshall (2000), spiritual intelligence is related to the practice and knowledge of individuals in dealing with and solving questions of meaning and value. In work environment, the belief system or value that an individual hold will help them improve their productivity. Therefore, burnout occurs when the belief system and values are diminished within the individual. The study of Moradi, Sadri, Khazan and Dargahi (2017) on the relationship between spiritual intelligence and burnout shows that there is a direct negative effect of spiritual intelligence on burnout. These findings prove that the spiritual intelligence in individuals can enhance creativity, honesty, trust, positive personal development, organizational commitment, job satisfaction, work engagement, work ethic, motivation, performance and productivity of work which prevent burnout.

According to Anderson (2006), physical intelligence refers to the awareness and use of body's senses for health and wellness support, providing information on environmental safety and comfort, and enhancing the development of one's life. According to Brock and Grady (2002), fatigue and lack of sleep due to changes and unstable sleep patterns are as a result of burnout. Other physical symptoms such as illness and being involved in minor accidents due to loss of focus are indications of individuals experiencing burnout. According to Koruklu, Feyzioglu, Ozenoglu-Kiremit and Aladag (2012), findings of burnout studies have shown psychological factors such as depression, stress, confusion, chronic anxiety, low self-esteem and frustration contributing to burnout. Therefore, physical intelligence is one of the individual factors contributing to the occurrence of burnout.

Buzan (2002) describes social intelligence as a measure of one's ability to interact in society and the ability to interact with people around him or her. Build good social support. Resilient individuals depend on others to help them through difficult times. They also need to develop good social support networks from friends and family to help reduce the impact of stress in life. Burnout is not a natural thing, it is a development of the social interaction that exists in the individual and the environment. The study of Girgin and Baysal (2005) shows that teachers who have social problems with their peers experience burnout in form of high emotions and depersonalization compared to those who receive social support from their peers.

Grotberg (1997) explained that resilience is the human capacity to meet challenges, overcome obstacles and gain strength through experiences and difficulties that have been experienced in life. According to Siebert (1996) individuals who are said to have resilience are better at situations where others find it difficult. People who have no resilience are said to have high risk of burnout. According to Pietarinen, Pyhalto, Soini and Salmela-Aro (2013) from a conceptual perspective, approaches to burnout syndrome and resilience are interrelated and derived from behavioral approaches to managing humans. Burnout can have an impact on motivation, satisfaction, quality of life and health. Resilience is a factor that can help reduce stress and burnout. The findings of Karimi and Adam's (2018) study, have shown that resilience is significantly associated with burnout.

According to maslach et. al (2001) identified several factors that are thought to contribute to burnout. These factors are workload, control, reward, community, fairness and values. These factors include resilience, emotional intelligence, social intelligence and spiritual intelligence. According to Krohne (2002), the theory of conservation of resources was introduced by Hobfoll in the early 1990s in his effort to establish a link between burnout and mental and physical health

The study was conducted to examine whether factors such as emotional intelligence, spiritual intelligence, physical intelligence, social intelligence affect resilience and burnout among high school teachers. The study also produced a model of the relationship between emotional intelligence, spiritual intelligence, physical intelligence and resilience with burnout.

\section{Methodology}

This is a quantitative approach study using survey design. The objective of the study is to identify the factors 
contributing to burnout among teachers. A total of 377 secondary school teachers participated in this study from 40 secondary schools in the state of Selangor which comprises of 10 districts.

The questionnaire used in this study to determine the relationship between emotional, spiritual, physical, social and physical intelligence based on the teacher's perspectives. Meanwhile, the data collection process is carried out only using the questionnaire form. This study only measure quantitative data and do not involve qualitative data also involved only secondary school teachers in the Selangor state as a sample.

Questionnaires were distributed and there are seven instruments used in this study. The Workplace Resilience Scale instrument is used to measure emotional, social, spiritual and social intelligence. Whereas to measure burnout, the Burnout Inventory has been used. This study uses two approaches in the process of data analysis, which are descriptive statistics using SPSS 22.0 software and inference statistics that use advanced analysis of Structural Equation Modeling (SEM) through Analysis of Moment Structure (AMOS) 22.0 software.

\section{Findings}

The findings show there are direct effects of emotional intelligence, physical intelligence, spiritual intelligence, social intelligence, resilience and burnout based on the nine hypotheses that have been tested. The hypotheses tested are as follows:

$H_{1}$ : There is a significant positive direct effect between

Emotional Intelligence (KE) and Resilience (DT)

$\mathrm{H}_{2}$ : There is a significant positive direct effect between

Social Intelligence (KSo) and Resilience (DT)

$H_{3}$ : There is a significant positive direct effect between

Physical Intelligence (KF) and Resilience (DT)

$\mathrm{H}_{4}$ : There is a significant positive direct effect between

Spiritual Intelligence (KS) and Resilience (DT)

$H_{5}$ : There is a significant negative direct effect between

Emotional Intelligence (KE) and Burnout (BO)
$H_{6}:$ There is a significant negative direct effect between Social Intelligence (KSo) and Burnout (BO)

$H_{7}$ : There is a significant negative direct effect on

Physical Intelligence $(K F)$ and Burnout $(B O)$

$H_{8}$ : There is a significant negative direct effect between Spiritual Intelligence (KS) and Burnout (BO)

$H_{9}$ : There is a significant negative direct effect between Resilience (DT) and Burnout (BO)

Hypothesis testing for direct effect was performed using the analysis of SEM-AMOS. Results of direct effects analysis for emotional intelligence $(\beta=.42$, $p$ $=.000)$, physical intelligence $(\beta=.29, \mathrm{p}=.000)$ showed significant positive values of resilience. Meanwhile, emotional intelligence $(\beta=-.85, p=.000)$, physical intelligence $(\beta=-.35, p=.000)$, spiritual intelligence $(\beta=$ $-.68, p=.000)$ and resilience $(\beta=-.78, p=.000)$ show a significant negative value with burnout. Therefore, these findings accept H1, H3, H5, H7, H8 and H9. The direct relationship can be described as, the higher the level of emotional intelligence and the physical intelligence of teachers, the stronger their resilience. Similarly, the higher the emotional intelligence, physical intelligence, spiritual intelligence and resilience, the burnout among teachers will be lower. However, the results of the direct effects analysis revealed no significant significance, namely on social intelligence $(\beta=.03, p=.571)$ and spiritual intelligence $(\beta=.09, p=.134)$ on resilience. On the other hand, social intelligence $(-.08, \mathrm{p}=.460)$ on burnout also shows a not significant result. This finding rejects the hypotheses $\mathrm{H} 2, \mathrm{H} 4$ and $\mathrm{H} 6$. The detailed report is listed in Table 1.

In total, six of the hypotheses tested (H1, H3, H5, H7, $\mathrm{H} 8$ and H9) were accepted. Meanwhile, the findings for $\mathrm{H} 2(\mathrm{KS} \rightarrow \mathrm{DT}, \beta=.03, \mathrm{p}=.571), \mathrm{H} 4(\mathrm{KSp} \rightarrow \mathrm{DT}, \beta$ $=.09, \mathrm{p}=.134)$ and $\mathrm{H} 6(\mathrm{KS} \rightarrow \mathrm{BO}, \beta=.08, \mathrm{p}=.460)$, indicate no effect of the direct relationship between the tested variables. The findings show that emotional intelligence and spiritual intelligence have nothing to do with a teacher's resilience. Similarly, social intelligence has nothing to do with burnout that occurs among teachers in schools.

Table 1. Result from hypothesis testing for direct effect analysis

\begin{tabular}{ccccc}
\hline Path & Relationship Prediction & $B$ & $P$ & Result \\
\hline $\mathrm{H}_{1}: \mathrm{KE} \rightarrow \mathrm{DT}$ & Positive & .42 & .000 & Accepted \\
$\mathrm{H}_{2}: \mathrm{KS} \rightarrow \mathrm{DT}$ & Positive & .03 & .571 & Rejected \\
$\mathrm{H}_{3}: \mathrm{KF} \rightarrow \mathrm{DT}$ & Positive & .29 & .000 & Accepted \\
$\mathrm{H}_{4}: \mathrm{KSp} \rightarrow \mathrm{DT}$ & Positive & .09 & .134 & Rejected \\
$\mathrm{H}_{5}: \mathrm{KE} \rightarrow \mathrm{BO}$ & Negative & -.85 & .000 & Accepted \\
$\mathrm{H}_{6}: \mathrm{KS} \rightarrow \mathrm{BO}$ & Negative & -.08 & .460 & Rejected \\
$\mathrm{H}_{5}: \mathrm{KF} \rightarrow \mathrm{BO}$ & Negative & -.35 & .000 & Accepted \\
$\mathrm{H}_{8}: \mathrm{KSp} \rightarrow \mathrm{BO}$ & Negative & -.68 & .000 & Accepted \\
$\mathrm{H}_{9}: \mathrm{DT} \rightarrow \mathrm{BO}$ & Negative & -.78 & .000 & Accepted \\
\hline
\end{tabular}

Notes: KE: Emotional Intelligence; KS: Social Intelligence; KF: Physical Intelligence; KSp: Spiritual Intelligence; DT: Resilience; BO: Burnout 
The model fits for the relationship between emotional intelligence, social intelligence, physical intelligence, spiritual intelligence and resilience and burnout as shown in Table 2. The values of fitting for the models of emotional intelligence, social intelligence, physical intelligence, spiritual intelligence and resilience and burnout have achieved minimum requirement for fitness with the study data. Indicators of RMSEA $=.103$ and GFI $=.987$ reinforced the findings of this model's compatibility analysis. The CFI $=.994$ and TLI $=.955$ values and the $\mathrm{CMIN} / \mathrm{df}=24.914$ values show that the model developed achieves good fit.

Table 2. Fit indices of emotional, social, physical, spiritual intelligence, resilience and burnout

\begin{tabular}{ccc}
\hline Index & Indicator & Result \\
\hline Absolute Fit Indice & $>.05$ & .000 \\
Prob (p-value) & $<.08$ & .103 \\
RMSEA & $>.90$ & .987 \\
GFI & & \\
Incremental Fit Indices & $>.90$ & .994 \\
CFI & $>.90$ & .955 \\
TLI & & \\
Parcimony Fit Indices & $<.50$ & 4.914 \\
Chisq/df & & \\
\hline
\end{tabular}

Figure 1 shows four variables that are predictors of burnout in this study: emotional intelligence (KE), social intelligence (KSo), physical intelligence (KF), spiritual intelligence (KSp) and endurance (DT). These variables are linked to form nine structural relationships. The findings show that these variables contribute to burnout in teachers in Malaysia. The relationships formed represent the relationship models of emotional intelligence, social intelligence, physical intelligence, spiritual intelligence and resilience and burnout achieved good fitness (Chisq / $\mathrm{df}=4.914, \mathrm{RMSEA}=1.03, \mathrm{CFI}=.994, \mathrm{GFI}=.987$, TLI $=.955$ ). The double correlation coefficient (SMC or R2) showed that $61 \%$ of the variance in burnout was explained by factor emotional intelligence, social intelligence, physical intelligence, spiritual intelligence and resilience. Furthermore, emotional intelligence, social intelligence, physical intelligence and spiritual intelligence showed a $\mathrm{R} 2$ value of $59 \%$ of the variance in resilience.

\section{Discussion}

Findings have shown that there is a significant positive direct effect on emotional intelligence and resilience. The findings of this study are in line with findings from the Study of Armstrong et al., (2011); Dhamodharan and Ravikumar (2014); Schneider, Lyons and Khazon (2013) who studied the relationship between resilience and emotional intelligence among 414 respondents aged 24 to 58 , showed how respondents respond to negative events in their lives. Respondents were placed in three groups based on their resilience, high or medium or low. The findings show that there is a positive relationship between resilience and emotional intelligence. Individuals in the higher resilience group were also reported to have high levels of emotional intelligence. A teacher needs emotional intelligence because it can help a teacher to act and be resilient. The findings also show that there is a significant positive direct effect on physical intelligence on resilience. This finding has been supported by studies of resilience also associated with physical activities that contribute to physical intelligence. Study by Cornu's (2009) MacFarlane and Montgomery (2010) found that resilience and physical activity contributed to physical intelligence and were positively related. They think that college careers are difficult and stressful, but the most natural way to gain resilience is to engage in physical activity that can help to increase physical intelligence. This physical intelligence will lead to high resilience and help in managing stress in your career. Monshouwer et al. (2012) conducted a similar study that investigated at the relationship between physical activity and resilience to control for the effects of social relations, self-image, socioeconomic status, gender and age. The findings of their study have shown that negative physical activity is related to mental health problems, as well as poor resilience. Therefore, a teacher needs to have physical intelligence at school or home as it helps teachers improve their service quality at school. The findings of the study have also shown that social intelligence and spiritual intelligence that do not affect resilience. The findings show that spiritual intelligence has a positive relationship with resilience. 


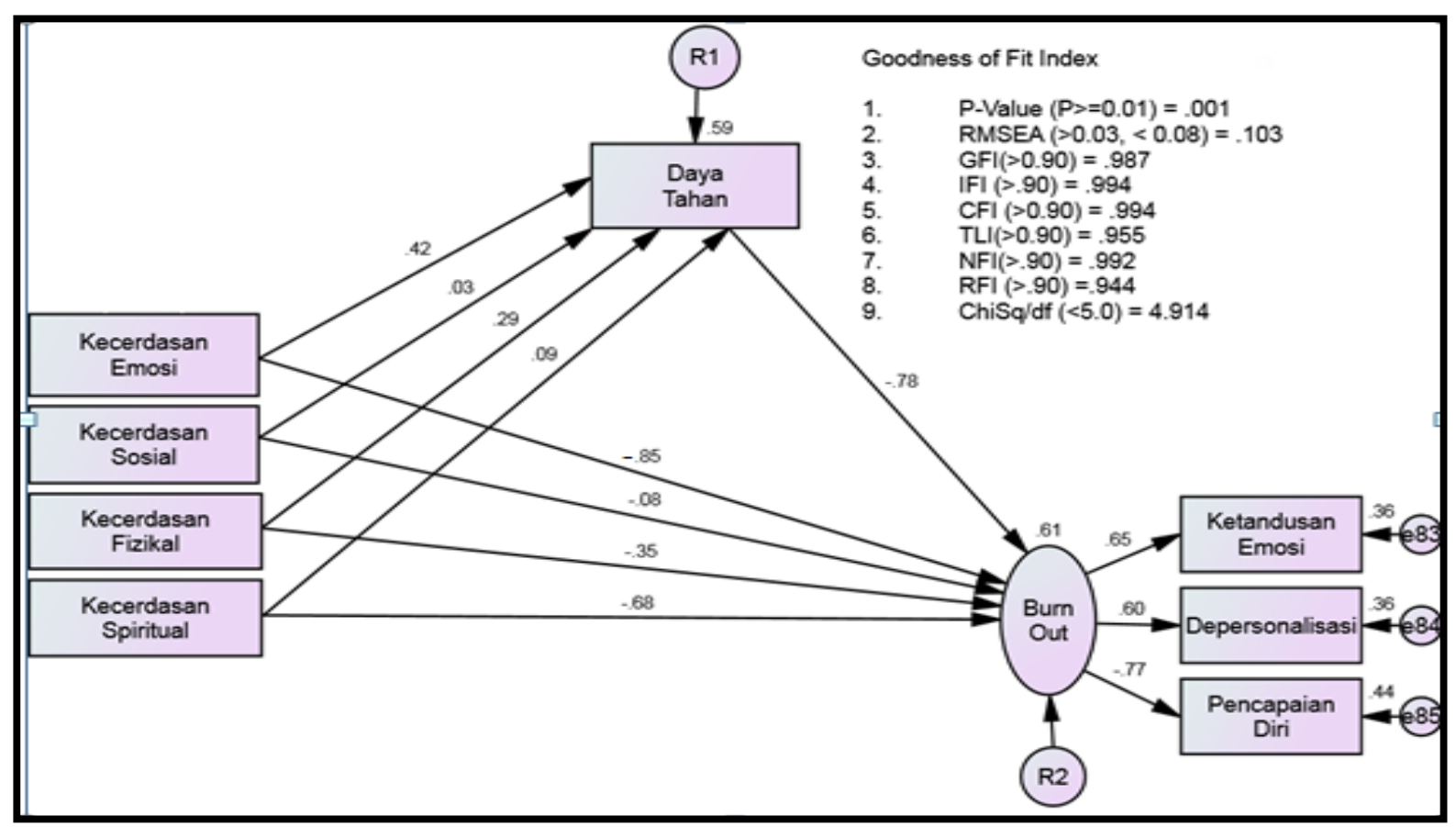

Figure 1. Structural models of relationship between emotional, spritual, physical, and social intelligence, resilience and burnout

The findings show that there is a significant negative direct effect on emotional intelligence and burnout. The findings of this study are in line with the findings of a study conducted by Alavinia and Ahmadzadeh (2012), Pishghadam and Sahebjam (2012), Robiatul Adawiyah (2013), Saiiari et al. (2011), Vaezi and Fallah (2011) and Zysberg et al. (2017) who conducted their respective studies in Iran, Spain and Indonesia on high school teachers. This situation clearly shows that a teacher with emotional intelligence will be able to control his emotions so that he can act rationally and will not suffer burnout. Emotional intelligence is also important in ensuring that teachers do not burnout. Teachers need to maintain their emotional intelligence especially in dealing with today's students. The study also found that spiritual intelligence also has an impact on burnout among teachers. This finding is supported by a study conducted by Moradi et al. (2017) who looked at the direct impact of spiritual intelligence on burnout among workers at Iran's Mohagnesh Ardarbi University who have shown $(\mathrm{p}>0.01,=-0.41)$ significance among spiritual intelligence with burnout. Psychologists believe that the major success of large organizations depends on the director and spiritual intelligence of their employees, Moradi et.al (2017). This study was also supported by Akbarizadeh, Bagheri, Hatami, Hajivandi (2012), Captari (2010), and Wachholtz and Rogoff (2013), respectively, looking at the effects of spiritual intelligence among medical students, nurses and college assistants at the university. Their research also shows that spiritual intelligence contributes to the occurrence of burnout. The findings of this study also show that there is a significant negative direct effect on physical intelligence and burnout. The findings show that the higher physical intelligence, the less risk of burnout. The findings of this study are supported by the study of Salvagioni et al., (2017) who stated that the physical effects that may have on those who are on burnout include hypercholesterolemia, diabetes, heart disease, cardiovascular disorders, muscle aches, chronic pain changes, prolonged fatigue, headache, gastrointestinal problems, respiratory problems, severe injuries and death under 45. Psychological effects include insomnia, depressive symptoms, use of psychotropic and antidepressant drugs, mental disorders and symptoms of psychological illness. These findings indicate that physical intelligence is one of the factors that affect burnout. There are some previous studies, which look at the aspects of social intelligence with burnout separately; studies that cover topics related to each other are limited. Although there are studies involving burnout and social intelligence or vice versa in areas other than teachers such as nursing (Taormina \& Law, 2000), human services (Liang \& Hsieh, 2008), and manufacturing workers (Gao, 2013), such studies directly combining teacher burnout and social intelligence have shown no effect on burnout. The findings of the previous study are the same as the findings of this study. However a study conducted by Lynn (2013) which examined how academic confidence, teacher socialization, and teacher diversity related to teacher burnout with 98 primary school teachers showed that academic and cohesive optimism was negatively associated with their emotional exhaustion and temporary discomfort that have a positive relationship with personal achievement. The findings also show that resilience contributes to burnout. The findings of this study are supported by the findings of De Saousa et al., (2018) showing that only 6\% of respondents with high resilience tend to burnout while 53\% 
say respondents say high resilience causes them not to have burnout. Their research has also shown that resilience is one of the predictors of burnout among teachers in higher education institutions. Among the dangers of resilience are self-efficacy, living conditions, calmness and resilience, each contributing to burnout. This can be attributed to the state of the teacher having a high degree of resilience to adapt to the situation, adaptive ability and overcome any obstacles that may arise in the workplace.

\section{Conclusion}

Overall the findings of this study have shown that the internal factors that contribute to burnout among teachers have been proven. These factors are emotional intelligence, spiritual intelligence, physical intelligence, social intelligence and resilience. Predictors of emotional intelligence, spiritual intelligence, physical intelligence, social intelligence and resilience can explain the contribution of burnout. This finding explains that it is important for a teacher to equip themselves with that intelligence and to have the ability to carry on with the task of enhancing student achievement which in turn motivates them to excel. This model of emotional, spiritual, physical intelligence and burnout is an important indicator for certain parties such as the Ministry of Education Malaysia to improve key elements in selecting a teacher and the courses that need to be taken to prevent such burnout from happening. This model can be used as a reference, in which ways changes and improvements can be made to teachers. The forms of the course and the content of the course also need to be reviewed by certain parties at the MOE to help teachers avoid burnout.

\section{REFERENCES}

[1] Akbarizadeh F, Bagheri F, Hatami HR, Hajivandi. (2012). A

[2] Relationship between nurses' spiritual intelligence with hardiness and general health. Journal of Kermanshah University of Medical Sciences (Behbood), 15(6), 466-72.

[3] Alavinia, P., \& Ahmadzadeh,T. (2012). Toward a Reappraisal of

[4] the Bonds between Emotional Intelligence and Burnout. English Language Teaching, 5(4), 37-50.

[5] Anbar, A. \& Eker, M. (2008). An Examination of Relationship between Burnout and Job Satisfaction among Turkish Accounting and Finance Academicians. Europian Jurnal of Economic and Political Studies, 1(1): 39 - 57.

[6] Anderson, R. (2006). Body intelligence scale: defining and measuring the intelligence of the body. The Humanistic Psychologist, 34(4), 357-367.

[7] Armstrong, A.R., Galligan R.F., Critchley, C.R. (2011).
Emotional Intelligence and Psychological Resilience to Negative Life Events. Personality and Individual Differences, 51(3), 331-336.

[8] Blazer, C. (2010). Teacher Burnout. Information Capsule Research Services, 1003, 1-22.

[9] Brock, B. L. \& Grady, M. L. (2002). Avoiding Burnout; A Principle's Guide to Keeping the Fire Alive. California: Corwin Press, Inc.

[10] Buzan, T. (2002). The Power of Social Intelligence. Noida: Gopsons Paper Ltd.

[11] Buzan. (1997). Rethinking security after the cold war. Cooperation and Conflict, 32(1), 5-28.

[12] Captari, D. (2010) Investigating the correlation between burnout and spirituality among resident assitants at Liberty University. MSc Thesis. Lynchburg, Virginia, United States: Liberty University

[13] Caspersen, J., \& Raeen, F. D. (2014). Novice teachers and how they cope. Teachers and Teaching Theory \& Practice, 20(2), 189-211.

[14] Cherniss, C. (2000). Emotional intelligence and organizational effectivenes, dlm. C. Cherniss \& D. Goleman (Editor). The emotionally intelligent workplace: How to select for, measure and improve emotional intelligent in individuals, groups and organizations San Fransisco: Jossey-Bass

[15] Cornu, R. L. (2009). Building Early Teacher Resilience: The Role of Realtionships. Teaching and Teacher Education, 22 (5) $717-723$.

[16] De Sousa, J. C., Pinto, F. R., De Lacerda Leite, J. C., De Pádua Araújo, A., Da Silva, P. M. M., \& De Castro, A. B. C. (2019). Relation between Burnout Syndrome and Resilience in Higher Teaching Activity. Mediterranean Journal of Social Sciences, 9(5), 177-186.

[17] Dhamodharan, V., \& Ravikumar, T. (2014). Relationship among Emotional Intelligence, Spiritual Intelligence and Psychological Resilience of Corporate Executives in India. Indian Journal of Appiled Research, 349-352.

[18] Farber, B. A. (1991). The Jossey-Bass Education Series Crisis in Education: Stress and Burnout in The American Teacher. San Francisco, CA, US: Jossey-Bass.

[19] Girgin, G., \& Baysal, A. (2005). Tükenmişlik Sendromuna Bir Örnek: Zihinsel Engelli Öğrencilere Eğitim Veren Öğretmenlerin Tükenmişlik Düzeyi. TSK Koruyucu Hekimlik Bülteni, 4(4), 172-187.

[20] Grotberg, E. H. (1997). The International Resilience Project. Presented at the Internationl Council Of Psychologist Confrence, Graz, Austria.

[21] Jeloudar, S. Y., Goodarzi, F. L. (2012). What is the relationship between spiritual intelligence and job satisfaction among MA and BA teachers? International Journal of Business and Social Science, 3(8), 299.

[22] Karimi, M. N., \& Adam, S. B. (2018). A structural equation modelling analysis of the relationships between perceived occupational stress, burnout, and teacher resilience. Journal of Second Language Teacher Education, 1(1), 49-72. 
[23] Koruklu, N., Feyzioglu, B., Ozenoglu-Kiremit, H., \& Aladag, E. (2012). Teachers' burnout levels in terms of some variables. Educational Sciences Theory \& Practice 12(3), $1823-1830$

[24] Lynn, S. J. (2013). Teacher burnout and its relationships with academic optimism, teacher socialization, and teacher cohesiveness. ETD Collection for Fordham University.

[25] Maslach, C, Jackson, S. E. (1981). The measurement of experienced burnout. Journal of Occupational Behaviour, 2, 99-113.

[26] Maslach, C. (2001). Preventing Burnout in Your Organization. California: Kantola Productions

[27] Maslach, C., Schaufeli, W. B., \& Leitar, M. P. (2001). Job Burnout. Annual Review Psychology, 52, 397- 422.

[28] Mayer, J. D., \& Salovey, P. (1997). What is emotional intelligence? In Salovey, P. \& Sluyter, D. (Editor). Emotional Development and Emotional Intelligence: Educational Implications. New York: Basic Books

[29] Monshouwer, K., Have, M. ten, Poppel, M. van, Kemper, H., \& Vollebergh, W. (2012). Possible mechanisms explaining the association between physical activity and mental health: Findings From the 2001 Dutch Health Behaviour in School-Aged Children Survey. Clinical Psychological Science.

[30] Moradi, M., Sadri Damirchi, E., Khazan, K., \& Dargahi, S. (2017). The mediating role of psychological capital on the relationship between spiritual intelligence and job burnout. Journal of Occupational Health and Epidemiology, 6(2), 84-91.

[31] Pietarinen, J., Pyhalto, K., Soini, T., \& Salmela-Aro, K. (2013). Reducing Teacher Burnout: A Sosio-Contextual Approach. Teaching and Teacher Education, 35, 62-72.

[32] Pishghadam,R.,\& Sahebjam,S. (2012). Personality and emotional intelligence in teacher burnout. The Spanish Journal of Psychology, 15(1), 227-236.

[33] Robiatul Adawiyah, R.A. (2013). Kecerdasan emosional, dukungan sosial dan kecenderungan burnout. Jurnal Psikologi Indonesia, 2(2), 99-107.

[34] Saiiari, A., Moslehi, M., \& Valizadeh, R. (2011). Relattionship between emotional intelligence and burnout syndrome in sport teachers of secondary schools. Procedia social and Behavioral Sciences, 15(4), 1786-1791.

[35] Schaufeli W.B, Maslach,C \& Marek, T. (1993). Professional Burnout, Recent Developments in Theory and Research. Taylor \& Francis.

[36] Schneider, T. R., Lyons, J. B., \& Khazon, S. (2013). Emotional intelligence and resilience. Personality and Individual Differences, 55(8), 909-914.

[37] Siebert, A. (1996). The Survivor Personality. New York, NY: Pedigree Books.

[38] Syed Ismail Syed Musthapa \& Ahmad Subki Miskon. (2013). Guru dan Cabaran Semasa. Puchong Selangor: Multimedia Sdn Bhd.

[39] Trapp, C. S. (2010). The association among emotional intelligence, resilience, and academic performance of preservice teachers, Phd Dissertation. University of Phoenix.

[40] Wachholtz A, Rogoff M. The relationship between spirituality and burnout among medical students. J Contemp Med Educ 1(2), 83-91.

[41] Zohar, D. \& Marshall, I. (2000). SQ: Spritual Intelligence: The Ultimate Intelligence. London: Bloomsbury. 